\title{
Dynamic Properties of Radial and Tangential Movements as Determinants of the Haptic Horizontal-Vertical Illusion with an $L$ Figure
}

\author{
Tong S. Wong \\ University of Stirling, Scotland
}

\begin{abstract}
In four experiments involving blindfolded subjects, constant errors in the haptic judgment of extent in the horizontal plane were found to relate consistently to the time and velocity of limb movement. Radial movements, executed at a slower speed and for a longer time, are judged longer than tangential movements of equal extent. The data were considered in relation to certain physiological and kinematic properties of the actively moving limb. Taken together with additional information on judgments of movement duration, the results suggest that the illusion of extent is modulated by the perception of differential time cues. In these terms, it was noted that the haptic horizontal-vertical illusion with the $L$ figure is another instance of the interaction of apparent space and time commonly found in studies of psychological relativity.
\end{abstract}

Following Reid's (1954) documentation of the haptic horizontal-vertical illusion with an $L$ figure, recent studies have shown that the effect is functionally related to the components of radial and tangential exploratory arm movements as described earlier by Davidon and Cheng (1964). Specifically, radial arm movements toward and away from the body, whether along the sagittal or coronal planes, are judged longer than equal tangential movements along the front or side of the body. The effect operates regardless of the spatial separation of the two extents to be judged (Cheng, 1968) and independently of two different types of movement involving different joints and muscle groups (Day \& Wong, 1971). As radial movements are specific to the horizontal plane, no relative overestimation of haptic extent is found when the $L$ figure is presented in the vertical (fronto-parallel)

Experiments 1, 2, and 3 were completed at the University of Waikato in Hamilton, New Zealand, and supported by New Zealand University Grants Committee Grant No. 72/29.

Requests for reprints should be sent to Tong $\mathrm{S}$. Wong, Department of Psychology, University of Stirling, Stirling FK9 4LA, Scotland, United Kingdom. plane (Cheng, 1968; Day \& Avery, 1970; Day \& Wong, 1971; Deregowski \& Ellis. 1972).

While it is clear that the illusion is related to the differential actions of the joints and muscles involved (Davidon \& Cheng, 1964), there remains the problem of delineating the specific stimulus features of limb movements that underlie the constant errors of judgment. The present study is concerned with this question.

In active touch it is reasonable to assume that variation in the dynamic properties of limb movement makes a difference in perceived extent. Such an analysis was suggested by Brown (1846/1964) and more recently by Reid (1954), who both argued but without supporting data that the slower the speed in traversing an extent, the greater the extent appears. Such a relationship in fact was demonstrated by Wapner, Weinberg, Glick, and Rand (1967), who found that with passive movement of the limb, a relatively faster (slower) speed gives rise to an apparently shorter (longer) extent. More recently, Ono (1969) has found the same relationship with active movement in line-drawing tasks wherein the longer lines are those drawn at the slower speed for a 
longer time. In these two studies, the speed of arm movement was the independent variable. With passive movement, the limb was moved at various speeds through its attachment to a movable finger plate; with active movement, the subject was instructed to draw lines at relatively fast or slow speeds.

From the available evidence, it seems reasonable to assume that the apparently longer radial movements are executed at a slower speed and for a longer time compared with tangential movements of equal extent. Experiments 1 and 2 confirmed this relationship and provided additional information on the judgment of haptic length in different planes of movement. Experiments 3 and 4 then were conducted to seek further information on the specific dynamic components of the movement that might underlie the differential perception of radial and tangential extents.

\section{Experiment 1}

By rotating the $L$ figure in $15^{\circ}$ increments over $90^{\circ}$, Deregowski and Ellis (1972) showed that the haptic horizontalvertical illusion is a special case of the more general radial-tangential effect (Cheng, 1968), wherein the two components of the $L$ figure are contrasted maximally by radial and tangential movements. This, as well as related past studies on the illusion have all employed comparative judgments where responses were made with reference to the standard component of the figure. If the effect is intrinsic to the properties of the moving limb, a more direct assessment can be made by instructing the subject to move the limb along standard distances prescribed verbally by the experimenter. Experiment 1 was conducted initially to confirm the occurrence of the radial-tangential effect under conditions where the subject made operative judgments of length in response to a verbal, rather than an objective, standard. The generality of the effect was also assessed by including in the design a factorial combination of some parameters of limb movement.

\section{Method}

Apparatus. The details of the apparatus are depicted in the upper half of Figure 1. Essentially, it consisted of two No. 11 gauge polished steel rods, each $45 \mathrm{~cm}$ long, a $180^{\circ}$ protractor, and a $40-\mathrm{cm}$ pointer rule graduated in millimeters. One rod could be rotated and secured along any orientation through $170^{\circ}$, while the other rod was fixed and aligned at $180^{\circ}$. The pointer rule was affixed at one end such that it could be swiveled at the point of intersection of the rods to an alignment below either of the rods. A 1.5-mm long tubular marker made of soft plastic was inserted through each rod. The marker could be slid along the rod effortlessly by the tip of the extended index finger, and it could maintain its rested position even when the rod was affixed in the vertical plane. The apparatus could be secured to a testing table through clamps and presented to the subject either in the vertical or horizontal plane.

Subjects. There were 42 unpaid volunteer subjects: 23 males and 19 females. Their age range was 17-32 years, with a mean age of 20 years. The subjects were randomly assigned to one of three experimental conditions, each consisting of 14 subjects.

Experimental design and procedure. In the first condition (horizontal-front), the apparatus was placed horizontally on a low table in front of the subject, so that movement of the index finger (in contact with the marker) along the rod at $90^{\circ}$ was radial, and movements along the rod at $0^{\circ}$ (to the subject's left) and $180^{\circ}$ (to the subject's right) were tangential. In the second condition (horizontal-side), the apparatus was placed horizontally on a low table at the subject's right side, again such that radial movements were executed along the rod at $90^{\circ}$ and tangential movements at $0^{\circ}$ (toward the subject's front) and $180^{\circ}$ (toward the subject's back). In the third condition (vertical-front), the apparatus was placed in the vertical plane fronto-parallel to the subject at the distance of the outstretched arm and index finger, so that movement of the finger along the rods was tangential at all orientations.

For each condition, judgments were made in accord with a factorial combination of seven rod orientations and four prescribed movement extents. Rod orientations were set at $0^{\circ}, 30^{\circ}, 60^{\circ}, 90^{\circ}$, $120^{\circ}, 150^{\circ}$, and $180^{\circ}$, whereas verbally prescribed extents were for movements of 3 in., 6 in., 9 in., and 12 in. $(7.5 \mathrm{~cm}, 15.2 \mathrm{~cm}, 22.8 \mathrm{~cm}$, and $30.5 \mathrm{~cm}$, respectively) along the rod. The standards were prescribed in inches as the subjects were not fully conversant with metric units; however, the judgments were recorded to the nearest millimeter. Each factor combination was repeated four times, so that each subject was presented with a total of 112 trials. A different random order of presentation trials was employed for each subject.

The subjects were seated and wore blindfold goggles. Before each trial the experimenter placed 

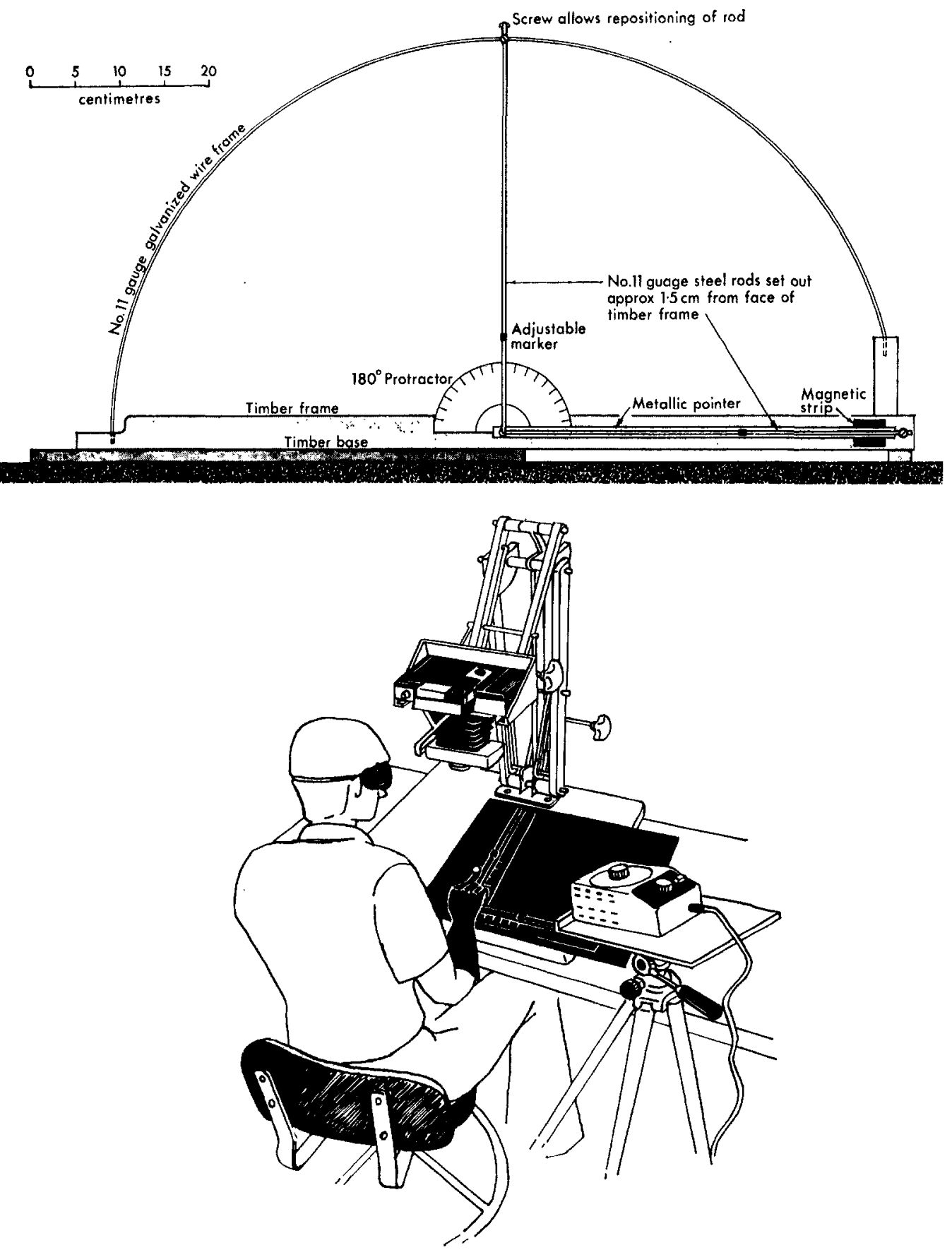

Figure 1. Upper half depicts apparatus employed in Experiment 1. (One rod could be rotated and secured along any orientation through $170^{\circ}$, while the other rod was fixed at $180^{\circ}$.) Lower half shows arrangements to obtain photographic records of subject's limb movements in Experiments 2 and 3 . (Polaroid camera recorded movement of light from stroboscope reflected off ball bearing adhered to subject's finger tip.) 


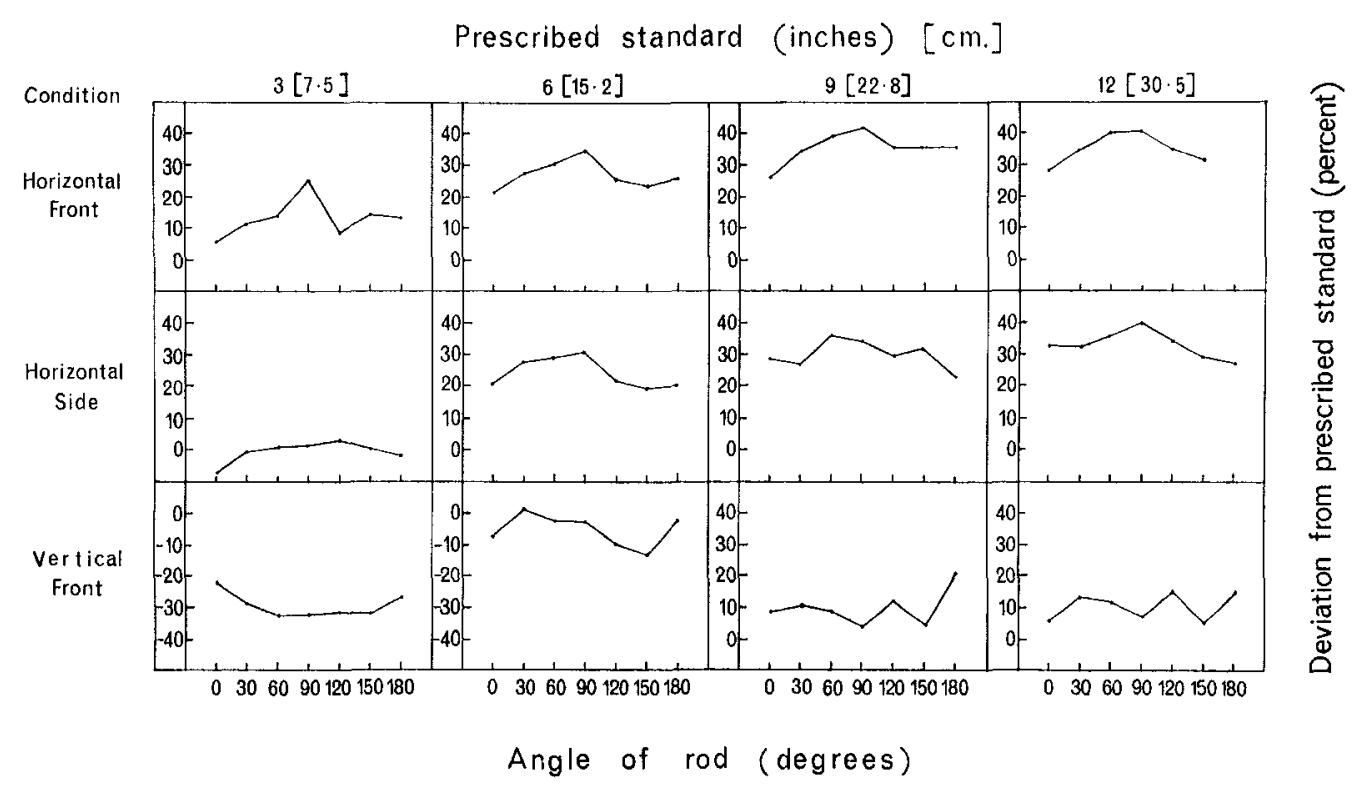

Figure 2. Operative movements from Experiment 1, expressed as percentage deviations from verbally prescribed standards, as a function of orientation of the arm from the body along different planes. (Positive percentages reflect movements shorter than prescribed standard and indicate overestimation of movement extent.)

the tip of the subject's outstretched index finger onto the plastic marker at the $0-\mathrm{mm}$ setting and instructed him to slide the marker along the rod over the verbally prescribed standard distance. Then the distance traversed was recorded through a visual alignment of the distal edge of the marker with the reading on the pointer rule situated immediately below. The recorded distance constituted the subject's operative judgment. This procedure was repeated over the 112 trials for each of the 14 subjects in each of the three experimental conditions.

\section{Results and Discussion}

The mean operative judgments and respective standard deviations for the stimulus conditions are shown in Table 1 . The deviation of the mean judgment from the prescribed standard was calculated and expressed as a percentage. An operative judgment less than the prescribed standard indicated an overestimation of the movement, and this was expressed as a positive percentage. The percentage scores served as convenient indexes to depict the patterns of constant errors, and these are shown in Figure 2.

It would be expected that the apparently longer radial movements should be indexed by relatively more positive percentage scores. An examination of Figure 2 indicates that the functions obtained for the horizontalfront and horizontal-side conditions conform to expectation in that the percentage scores are generally more positive at $90^{\circ}$ than at $180^{\circ}$ and $0^{\circ}$. However, this general trend is not evident among the data obtained for the vertical-front condition.

Separate analyses of variance were carried out for each of the three conditions. For the horizontal-front condition, both orientation of the rod, $F(6,351)=4.351$, $p<.0005$, and prescribed standard, $F(3$, $351)=316.701, p<.0005$, were significant factors, but the Orientation $\times$ Prescribed Standard interaction was not significant, $F(18,351)<1, p>.05$. Similarly for the horizontal-side condition, both orientation, $F(6,351)=3.567, p<.005$, and prescribed standard, $F(3,351)=372.818, p<.0005$, were significant factors, but the interaction between them was not significant, $F(18$, $351)<1, p\rangle .05$. For the vertical-front condition, orientation, $F(6,351)=5.899$, $p<.0005$, prescribed standard, $F(3,351)$ 
Table 1

Mean and Standard Deviation of Operative Judgment (in $\mathrm{cm}$ ) as a Function of Extent and Orientation of Movement of the Arm Along Different Planes of the Body in Experiment 1

\begin{tabular}{|c|c|c|c|c|c|c|c|}
\hline \multirow{2}{*}{$\begin{array}{l}\text { Prescribed } \\
\text { standard }^{a}\end{array}$} & \multicolumn{7}{|c|}{ Orientation of movement } \\
\hline & $0^{\circ}$ & $30^{\circ}$ & $60^{\circ}$ & $90^{\circ}$ & $120^{\circ}$ & $150^{\circ}$ & $180^{\circ}$ \\
\hline \multicolumn{8}{|c|}{ Horizontal-Front plane } \\
\hline \multicolumn{8}{|l|}{$7.5 \mathrm{~cm}$} \\
\hline$M$ & 6.56 & 6.62 & 6.44 & 5.58 & 6.76 & 6.45 & 6.51 \\
\hline$S D$ & 2.47 & 2.26 & 2.06 & 1.53 & 1.73 & 1.54 & 1.99 \\
\hline \multicolumn{8}{|l|}{$15.2 \mathrm{~cm}$} \\
\hline$M$ & 11.91 & 11.03 & 10.57 & 9.97 & 11.30 & 11.61 & 11.25 \\
\hline$S D$ & 3.74 & 3.49 & 4.27 & 2.50 & 3.34 & 3.89 & 2.12 \\
\hline \multicolumn{8}{|l|}{$22.8 \mathrm{~cm}$} \\
\hline$M$ & 16.77 & 14.96 & 13.91 & 13.42 & 14.73 & 14.66 & 14.71 \\
\hline$S D$ & 5.46 & 4.93 & 3.43 & 4.60 & 4.86 & 3.99 & 4.39 \\
\hline \multicolumn{8}{|l|}{$30.5 \mathrm{~cm}$} \\
\hline$M$ & 21.88 & 19.89 & 18.30 & 18.25 & 17.99 & 19.85 & 20.89 \\
\hline$S D$ & 7.06 & 6.26 & 4.78 & 5.47 & 4.70 & 6.33 & 6.75 \\
\hline \multicolumn{8}{|c|}{ Horizontal-Side plane } \\
\hline \multicolumn{8}{|l|}{$7.5 \mathrm{~cm}$} \\
\hline$M$ & 8.10 & 7.53 & 7.47 & 7.37 & 7.30 & 7.49 & 7.59 \\
\hline$S D$ & 3.72 & 3.03 & 2.92 & 2.92 & 3.07 & 3.00 & 3.61 \\
\hline \multicolumn{8}{|l|}{$15.2 \mathrm{~cm}$} \\
\hline$M$ & 12.06 & 11.09 & 10.80 & 10.63 & 11.97 & 12.34 & 12.12 \\
\hline$S D$ & 4.54 & 3.93 & 3.27 & 4.77 & 3.44 & 4.03 & 3.56 \\
\hline \multicolumn{8}{|l|}{$22.8 \mathrm{~cm}$} \\
\hline$M$ & 16.32 & 16.78 & 14.69 & 15.09 & 16.13 & 15.63 & 17.48 \\
\hline$S D$ & 5.72 & 6.81 & 3.98 & 5.34 & 6.58 & 5.09 & 5.80 \\
\hline \multicolumn{8}{|l|}{$30.5 \mathrm{~cm}$} \\
\hline$M$ & 20.51 & 20.70 & 19.72 & 18.52 & 20.10 & 21.58 & 22.25 \\
\hline$S D$ & 5.50 & 7.41 & 6.89 & 5.01 & 7.05 & 5.98 & 5.76 \\
\hline \multicolumn{8}{|c|}{ Vertical-Front plane } \\
\hline \multicolumn{8}{|l|}{$7.5 \mathrm{~cm}$} \\
\hline$M$ & 9.15 & 9.66 & 9.93 & 9.95 & 9.90 & 9.90 & 9.53 \\
\hline$S D$ & 3.10 & 3.48 & 3.59 & 4.36 & 4.28 & 3.55 & 4.18 \\
\hline \multicolumn{8}{|l|}{$15.2 \mathrm{~cm}$} \\
\hline$M$ & 16.27 & 15.06 & 15.61 & 15.64 & 16.72 & 17.22 & 15.63 \\
\hline$S D$ & 3.58 & 4.89 & 5.79 & 4.84 & 5.02 & 4.93 & .4 .93 \\
\hline \multicolumn{8}{|l|}{$22.8 \mathrm{~cm}$} \\
\hline$M$ & 20.86 & 20.52 & 20.94 & 21.97 & 20.16 & 21.90 & 18.17 \\
\hline$S D$ & 6.31 & 4.65 & 6.85 & 5.12 & 6.23 & 5.72 & 4.41 \\
\hline \multicolumn{8}{|l|}{$30.5 \mathrm{~cm}$} \\
\hline$M$ & 28.95 & 26.66 & 27.10 & 28.50 & 26.02 & 29.02 & 26.07 \\
\hline$S D$ & 6.65 & 6.11 & 6.42 & 7.16 & 6.96 & 6.00 & 5.60 \\
\hline
\end{tabular}

- During the actual presentation of Experiment 1, subjects' prescribed standards were in inches (7.5 $\mathrm{cm}=3$ in., $15.2 \mathrm{~cm}=6$ in., $22.8 \mathrm{~cm}=9$ in., and $30.5 \mathrm{~cm}=12 \mathrm{in}$.).

$=555.951, p<.0005$, and the Orientation $x$

Prescribed Standard interaction, $F(18,351)$ $=6.991, p<.0005$, were all significant factors.

The mean operative judgments, pooled across the four prescribed standards, were further analyzed to determine the nature of the function across the seven rod orientations. For the horizontal-front and horizontal-side conditions, respectively, only the quadratic trend components were significant: $F(1,178)=17.284, p<.001$; and 


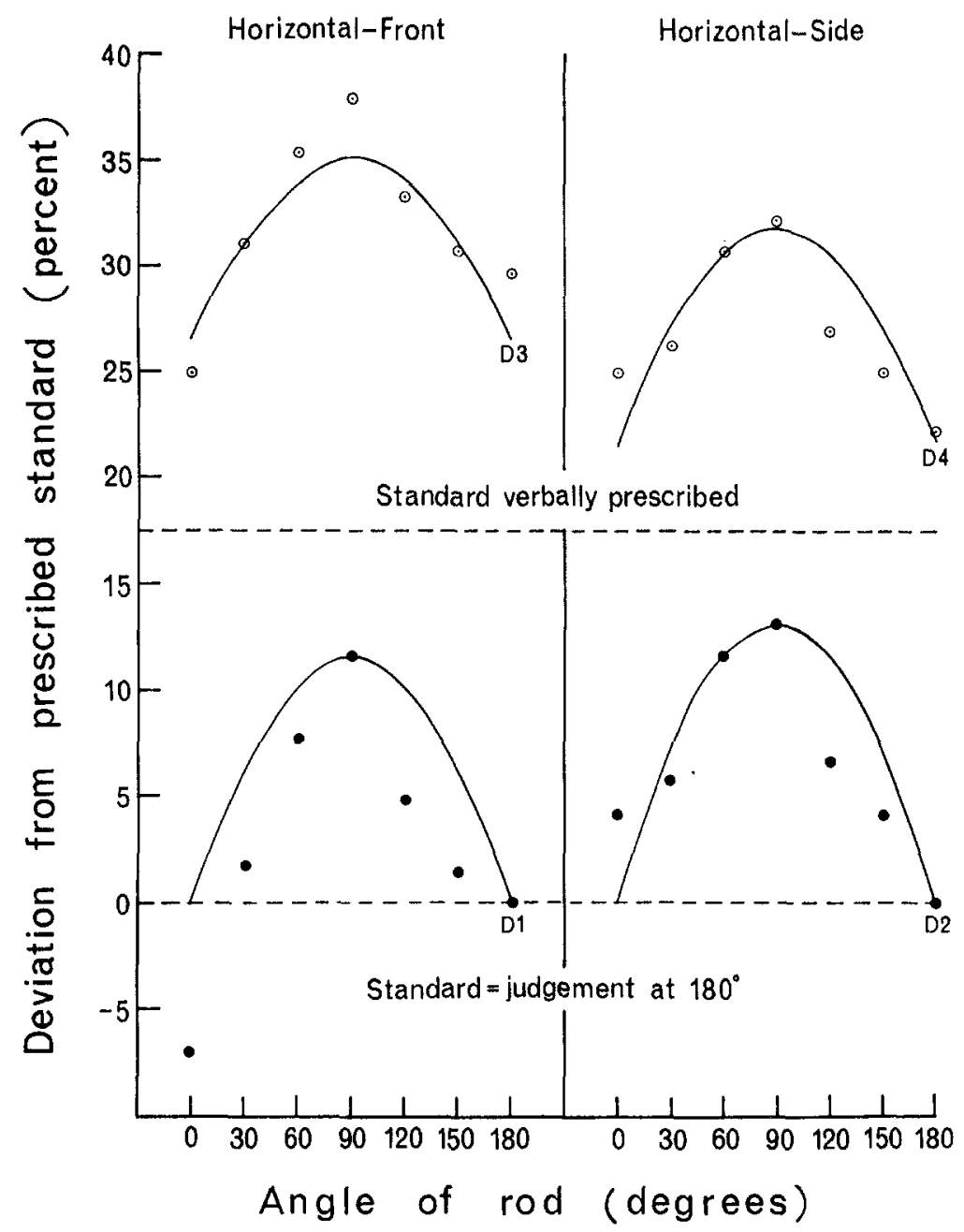

Figure 3. Mean operative movements from Experiment 1, expressed as percentage deviations from verbally prescribed standards (upper half) and from standards obtained from judgments at $180^{\circ}$ (lower half). (Curves $D_{1}, D_{2}, D_{3}$, and $D_{4}$ are theoretically derived functions as described in the text. Apparently longer movements are indexed by larger percentage scores.)

$F(1,178)=12.833, p<.001$. The absence of a significant linear trend for either condition indicates that the radial-tangential effect is symmetrical about the maxima at $90^{\circ}$.

In keeping with the approach adopted by Deregowski and Ellis (1972), it may be assumed that a radial movement is always overestimated by a constant factor $K$ and that a perceived extent is a sum of the prescribed extent and its illusory radial overestimation. Thus, in the horizontal-front condition, the ratio of the radial movement extent at $90^{\circ}$ (a) to the tangential component at $180^{\circ}(b)$ is given by

$$
a / b=[1+K(\sin \alpha)] /[1+K(\cos \alpha)],
$$

where $\alpha$ is the angle of the component rod to the subject's sagittal plane. The same equation can be applied to the horizontalside condition where $\alpha$ is the angle of the component rod to the subject's coronal plane. Given the values $a$ and $b$ from the obtained data, the value of $K$ could be de- 
termined and used in predicting values of operative judgments at other angles. These theoretical curves, $\mathrm{D}_{1}$ and $\mathrm{D}_{2}$, are shown in the lower half of Figure 3, together with the percentage scores calculated with respect to the arbitrary standard judgment at $180^{\circ}$. These results thus can be directly compared with previous studies involving comparative judgments. Similar functions, $\mathrm{D}_{3}$ and $\mathrm{D}_{4}$, were also derived using the operative judgments directly. These are shown in the upper half of Figure 3. It can be seen that the theoretical functions provide reasonable fits to the empirical data points.

As judgments were made operatively, the patterns of constant errors can be ascribed directly to the intrinsic action of radial and tangential arm movements such that the extent is perceived as longest when the movement is purely radial and shortest when purely tangential. These results corroborate those of earlier studies (Davidson \& Cheng, 1964; Day \& Wong, 1971; Deregowski \& Ellis, 1972) in which comparative judgments were employed. The significant orientation and Orientation $\times$ Prescribed Standard effects obtained for the vertical-front condition merit a further comment. This orientation effect in the vertical plane cannot be related to the operation of any systematic factor (see Table 1 and Figure 2) and, taken in conjunction with its significant interaction with the degree of executed movement, probably reflects the fortuitous influence of local constraints (and therefore affects the speed) of the arm in transit.

\section{Experiment 2}

Keeping to the paradigm adopted in Experiment 1, Experiment 2 was conducted to determine if the speed of radial movements is less than that for tangential movements.

\section{Method}

Apparatus. The apparatus was essentially the same as that employed in Experiment 1 except the rods were painted a mat black, and the tubular markers and pointer rule were removed. To record the duration and extent of executed movement, a
Land Polaroid camera (Model 350 with Close-Up Kit 563) and a transistorized stroboscope (Tourostrobe Type $551 \mathrm{XW}$ ) were employed.

Subjects. There were 50 unpaid volunteer subjects: 32 males and 18 females. Their age range was 18-26 years, with a mean age of 20 years.

Experimental design and procedure. Both the horizontal-front and horizontal-side experimental conditions as described in Experiment 1 were employed with the following modifications: For each condition, the subject was only required to make an operative judgment of 6 in. $(15.2 \mathrm{~cm})$ at each rod setting of $0^{\circ}, 45^{\circ}, 90^{\circ}, 135^{\circ}$, and $180^{\circ}$. A different random order of presenting the rod settings was employed for each of the 25 subjects in each condition. For each judgment, a record was obtained of both the extent and duration of operative movement (described below).

A polished steel ball bearing of $6.35-\mathrm{mm}$ diameter was attached to the tip of the subject's index finger nail with dark plasticine. In a darkened room and with both the Polaroid camera and flashing stroboscope placed at vantage positions, a photographic trace of the movement could be obtained through the reflected light of the ball bearing. The experimental arrangements are illustrated in the lower half of Figure 1 , except here an $L$ figure (for Experiment 3) is shown. Preliminary observations indicated that items in the stimulus field barring the ball bearing had to be adequately blacked out to produce an optimal photographic record. This precaution included covering the subject's limb with a long black nylon glove so that only the index finger tip with the attached ball bearing was exposed to the camera's view. With the stroboscope set at a rate of 10 flashes/sec, a movement extent was recorded clearly as a delineation of bright dots each representing a duration of $1 / 10$ sec.

On the signal "start" from the experimenter, the subject moved the tip of his index finger along the rod to delimit an apparent extent of 6 in. $(15.2 \mathrm{~cm})$. The experimenter activated the camera instantaneously upon giving the signal and terminated the exposure when the subject ceased movement and said "stop." The subject was instructed to move at a moderate speed that was comfortable to him. For each subject, the five operative movements were recorded on black and white film (Land Film Type 107) using the same exposure frame, so that the finished print showed all five movement extents. These were measured to the nearest $1 / 4 \mathrm{~cm}$ by using a small divider to calibrate the recorded movement extent against a photographic print of a $30-\mathrm{cm}$ rule exposed at precisely the same five rod orientations. The duration for each movement extent was measured to the nearest $1 / 10 \mathrm{sec}$ by counting the total number of light dots that delineated the respective extent. This could be readily accomplished with the naked eye, but where necessary a magnifying glass was used. 


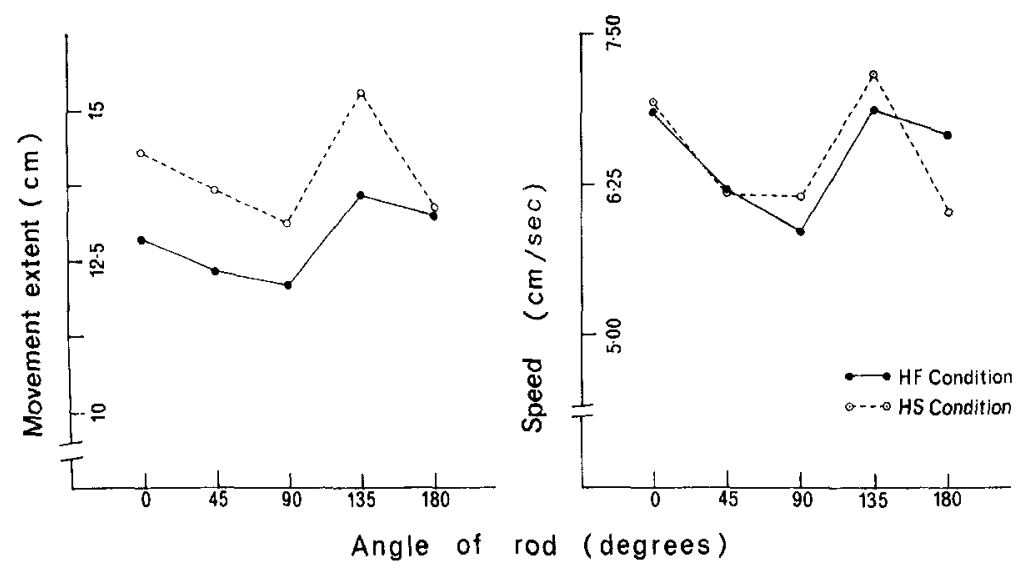

Figure 4. Obtained functions of operative movement extent and speed of movement of the arm along different orientations in the horizontal plane in Experiment 2. (HF denotes movements in front of subject, HS to the right side. Apparently longer extents are indexed by shorter operative movements.)

\section{Results and Discussion}

The mean operative judgments (movement extents) and corresponding movement speeds across the five orientations of the rod are shown in Figure 4. These data support those obtained in Experiment 1 in showing that the maximally radial movement component at $90^{\circ}$ for both the horizontal-front and horizontal-side conditions was judged longer than the movement components departing from $90^{\circ}$. The respective analyses of variance indicated values of $F(4,96)=3.762, p<.01$, and $F(4,96)=$ $5.718, p<.001$. The functions relating the speed of movement to the orientation of the rod indicate that radial movements at $90^{\circ}$ were executed slower than movements departing from $90^{\circ}$, with the sole exception of the component at $180^{\circ}$ for the horizontalside condition. The forms of the functions relating movement distance and speed, respectively, to movement orientation are essentially similar.

By analyzing the data in terms of a covariance design with randomized blocks (Kirk, 1968, p. 475), three correlation coefficients could be computed between operative judgments and the speed of arm movement across the five movement directions. For the horizontal-front condition, the overall correlation, $r \mathrm{~T}(123)=.413, p<.01$, the correlation between treatment level means, $r \mathrm{~B}(4)=.900, p<.05$, and the weighted average correlation, $r W(24)=.400, p<$ .05 , were all signficant. Similarly, significant results were obtained for the horizontal-side condition: $r \mathrm{~T}(123)=.518, p<$ $.01 ; r \mathrm{~B}(4)=.924, p<.01$, and $r \mathrm{~W}(24)$ $=.495, p<.01$.

Taken together, the results of Experiment 2 indicate that the radial-tangential effect is functionally related to the speed of limb movements in the horizontal plane. Specifically, the apparently longer radial movements are executed at slower speeds compared with those for the apparently shorter tangential movements. These results are in line with earlier suggestions (Brown, 1846/ 1964; Reid, 1954) and confirm previous haptic studies involving both passive (Wapner et al., 1967) and active (Ono, 1969) limb movements.

\section{Experiment 3}

The findings of Experiment 2 imply that for the haptic $L$ figure with components of equal length, the apparently longer radial extent is associated with a slower movement executed for a longer time. Thus, both differences in time and velocity cues are associated with the illusion of extent. Current physiological data suggest that control sys- 
Table 2

Mean Movement Duration (sec) and Standard Deviation Across Successive Locations of the L Figure in Experiment 3

\begin{tabular}{|c|c|c|c|c|c|c|c|c|c|c|c|}
\hline \multirow{2}{*}{$\begin{array}{l}\text { Movement } \\
\text { extent }\end{array}$} & \multicolumn{10}{|c|}{ Successive locations $(\mathrm{cm})$ from dichosection of $L$ figure } & \multirow[b]{2}{*}{ Total } \\
\hline & 1 & 2 & 3 & 4 & 5 & 6 & 7 & 8 & 9 & 10 & \\
\hline \multicolumn{12}{|l|}{ Radial } \\
\hline Duration & 1.245 & .340 & .255 & .235 & .215 & .230 & .245 & .230 & .245 & .560 & 3.765 \\
\hline$S D$ & .323 & .142 & .160 & .113 & .126 & .117 & .099 & .080 & .114 & .181 & 1.038 \\
\hline \multicolumn{12}{|l|}{ Tangential } \\
\hline Duration & 1.145 & .280 & .225 & .200 & .185 & .210 & .195 & .230 & .255 & .420 & 3.345 \\
\hline & .367 & .128 & .085 & .072 & .093 & .085 & .099 & .092 & .082 & .100 & .752 \\
\hline
\end{tabular}

tems for displacement, speed, and the force of movements are intricately linked (Brooks \& Stoney, 1971). This further implies that the force and, in the case where the mass of the limb is constant, the acceleration components of radial and tangential movements may also contribute to the illusion. Accordingly, Experiment 3 was conducted, using the haptic $L$ figure, to obtain additional information on the time, velocity, as well as acceleration characteristics of radial and tangential movements.

\section{Method}

Apparatus. The apparatus consisted of a $45 \times$ $45 \times 1 \mathrm{~cm}$ black Masonite board on which were secured two No. 11 gauge polished steel rods, each measuring $36 \mathrm{~cm}$ in length. The rods were secured $3.0 \mathrm{~cm}$ from the surface of the board and arranged in the form of an $L$ figure with the conjoining ends meeting at right angles. This point of dichosection was cut and machined so that the ends abutted onto each other leaving no gap and the upper surfaces of the rods flush. Adjacent to each component of the $L$ a $30-\mathrm{cm}$ black plastic ruler, calibrated in $\mathrm{mm}$ in gold lettering, was fixed and aligned in parallel. The flat surfaces of the rulers were just below the upper parts of the rods. A gap of $1.0 \mathrm{~cm}$ separated the longitudinal edge of each ruler from the respective rod. A brass slider, $1.0 \mathrm{~cm}$ diameter in cross section and $1.2 \mathrm{~cm}$ long, was attached to each rod so that it could be slid and secured along any desired position on the rod. The inner face of the slider delimited the prescribed extent for the moving index finger. The rods and attached sliders were painted a mat black.

Subjects. There were 20 unpaid volunteer subjects: 12 males and 8 females. Their age range was $18-22$ years, with a mean age of 20 years.

Procedure. The procedure was similar to that employed in Experiment 2, except here the $L$ figure was employed. The experimental arrangements are as those depicted in the lower half of Figure 1. The stimulus figure was presented in the horizontal-front condition, such that one component of the figure was radial and the other tangential. Both components of the $L$ were set equal at 10 $\mathrm{cm}$. The subject was instructed to move his index finger along the $L$ figure at a moderate speed, after which he was required to indicate whether the radial or tangential component felt longer (in length). For each recording, the subject traversed each component of the $L$ twice, beginning and terminating at the dichosection. The starting movement direction was counterbalanced across subjects. Only one photographic record was obtained from each subject. From the finished print, the relative duration of movement along successive $1-\mathrm{cm}$ portions of the figure could be determined by counting the number of light dots (each of $1 / 10 \mathrm{sec}$ duration) outlined beside respective portions of the rulers. The gold-lettered calibrations of the rulers could be seen clearly through the reflected light of the stroboscope.

\section{Results and Discussion}

Of the 20 subjects, 19 subjects indicated that the radial extent felt longer (in length), while one subject judged the tangential component to be longer. This difference in responses is significant $(p<.001)$ by the binomial test. The duration of movement and respective standard deviations across successive locations of the $L$ figure are shown in Table 2. These data on movement time were analyzed in accordance with a $2 \times 10$ (Movement Direction $\times$ Location) repeated measures design. Significant differences were found between movement directions, $F(1,361)=13.011, p<.001$, be- 


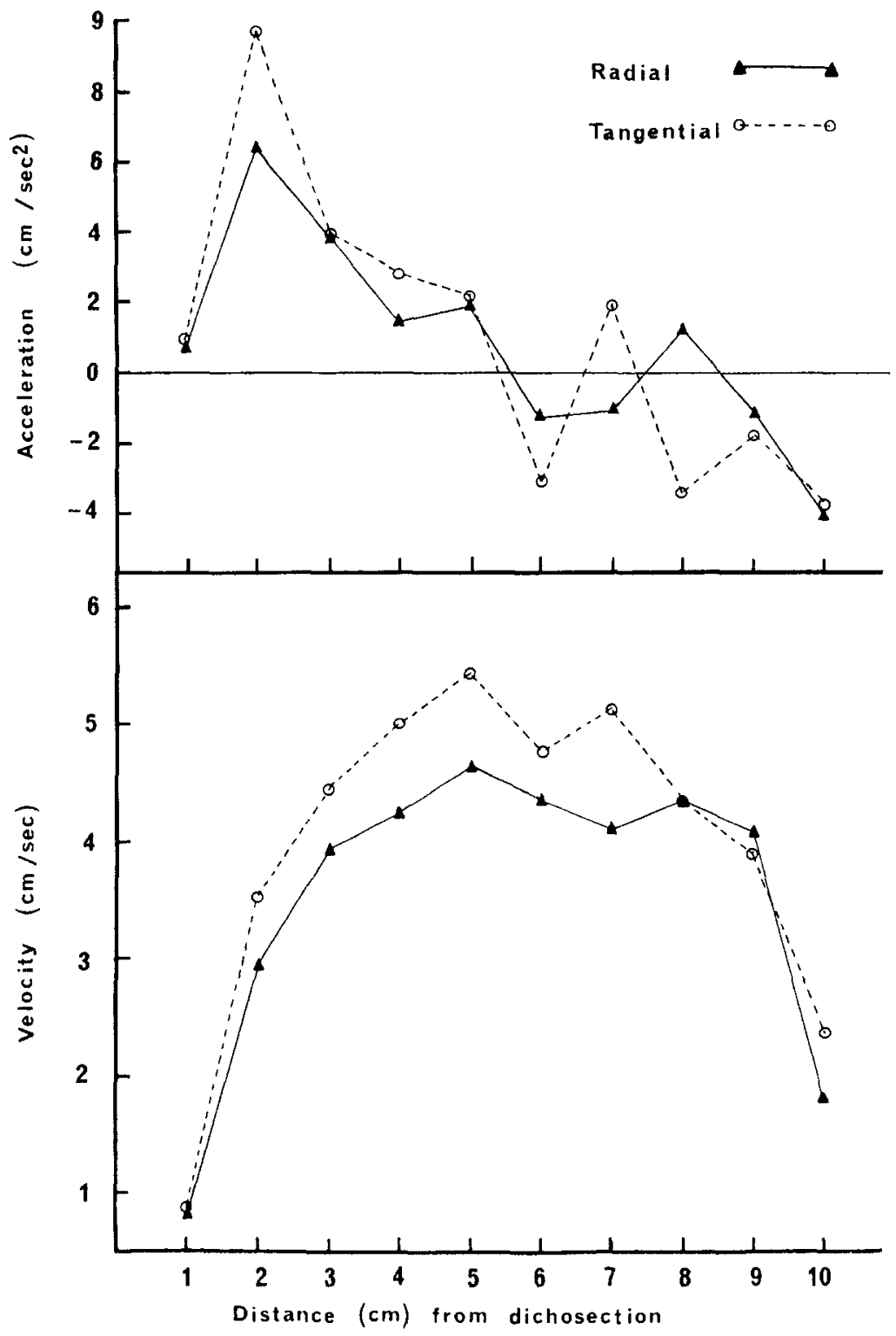

Figure 5. Velocity and acceleration characteristics of radial and tangential movements from Experiment 3 as a function of the distance from the dichosection of the $L$ figure.

tween locations, $F(9,361)=236.065, p<$ .001 , and for the interaction between movement directions and location, $F(9,361)=$ $5.318, p<.001$. These results indicate that movement along the radial component of the figure takes a longer time to execute compared with the tangential, and that the patterns of movement time across the two extents are different. ${ }^{1}$ From these data, further information was derived concerning the velocity and acceleration characteristics of the movements as a function of the distance

1 In a supplementary experiment involving a further 14 subjects, it was found that the difference in radial and tangential movement times remained unchanged with repeated measurements over trials. 
from the dichosection of the $L$ figure. These results are shown in Figure 5. As the anal$y$ sis of the data on movement durations already indicated, the velocity of the tangential movement is clearly greater compared with that for the radial. However, no clear interpretation can be made of the clata on the differences between the acceleration characteristics of radial and tangential movements.

From these results, it seems unlikely that acceleration cues, in the present context, can directly contribute to the illusion of extent. This analysis is in accord with previous observations of the illusion of extent under conditions that precluded the operation of acceleration cues when real movement is either passive (Wapner et al., 1967) or absent altogether in cutaneous perception (Helson \& King, 1931; Jones, 1956; Wieland, 1960).

With respect to the observed relationship between both time and velocity to judged extent, the physiological (Brooks \& Stoney, 1971) and psychological literature (Keele, 1968) suggest that the interrelationship of these variables is complex and does not lend itself to a single interpretation. The specific relationship may be governed by the points of emphasis of particular experiments. In this regard, Reid (1954) has observed from introspective reports that under conditions that give rise to the haptic $L$ illusion, the subjects attempt to keep the speed of movement constant while estimating the duration of movement. Thus, the apparently longer radial extent is presumably preempted by a judgment of greater elapsed time. This issue is examined in Experiment 4.

\section{Experiment 4}

Experiment 4 was conducted to determine if subjects could make accurate judgments of movement durations under conditions that produced the haptic $L$ illusion. If the illusion of extent were governed by the discrimination of differential movement times along radial and tangential directions, it could be expected that the perception of movement durations would be veridical,

\section{Method}

Apparatus. The stimulus $L$ figure employed was essentially the same as that described in Experiment 3. Two digital timers (Forth Instruments, Edinburgh) were also employed to record the actual duration of limb movements.

Subjects. There were 12 unpaid volunteer subjects: 2 males and 10 females. Their age range was $17-20$ years, with a mean age of 19 years.

Procedure. The general experimental conditions of testing were similar to those described in Experiment 3 , except here the subject was required to judge the relative duration of movement along the radial and tangential extents while attempting to keep the velocity of limb movement constant along both extents. For each trial, the experimenter operated a microswitch to synchronize with the observed movement along the radial and tangential component, so that the actual durations of these novements were recorded separately by the two digital timers.

By changing the relative length of the components of the $L$ figure along with judgments of duration, a point of subjective equality (PSE) for the length of the two extents could also be derived. This was accomplished by using the double-staircase technique (Wetherill, 1963; Wetherill \& Levitt, 1965). Each staircase started with the tangential extent (standard) equal to the $20-\mathrm{cm}$ radial component (variable) and was replaced by a shorter or longer variable according to the subject's judgment of relative duration. Thus, a "longer" response (in time) for the variable resulted in its decrease in one step size (in length) for the next trial in the same staircase series. Steps of $1.0 \mathrm{~cm}$ were used until six reversals of judgment from "longer duration" to "shorter duration" (or vice versa) occurred. The mean of the six variable lengths that resulted in a reversal of judgment constituted the PSE.

\section{Results and Discussion}

In accord with Experiments 2 and 3, the mean movement time of $10.468 \mathrm{sec}(S D=$ $6.625 \mathrm{sec}$ ) obtained for the radial component is significantly longer, $t(11)=4.120, p<$ .005 , than that of $9.105 \mathrm{sec}(S D=5.955$ $\mathrm{sec})$ for the tangential. To determine if subjects in fact could perceive a difference in the relative movement times for the two movement directions, the total number of judgments on relative duration from all subjects were categorized in the form of a $2 \times$ 2 contingency table as shown in Table 3 . These results indicate that the subject's judgments of relative duration were more often correct than not, $\chi^{2}(1)=10.603, p<$ 
Table 3

Frequency of Judgment of Relative Duration Against Actual Relative Duration of Radial and Tangential Movements in Experiment 4

\begin{tabular}{lccc}
\hline \multirow{2}{*}{$\begin{array}{c}\text { Actual } \\
\text { relative } \\
\text { duration }\end{array}$} & \multicolumn{3}{c}{ Judged relative duration } \\
\cline { 2 - 4 } & $\begin{array}{c}\text { Radial } \\
\text { longer }\end{array}$ & $\begin{array}{c}\text { Talngential } \\
\text { longer }\end{array}$ & Total \\
\hline Tangential longer & 11 & 18 & 29 \\
Radial longer & 89 & 38 & 127 \\
Total & 100 & 56 & 156 \\
\hline
\end{tabular}

.01. The corresponding phi coefficient between subjects' judgments of relative duration and the actual relative time is .252 $(p<.01)$. To assess the role of the velocity of movement on apparent duration, velocity data were also derived and analyzed in the same manner as the data on duration. If velocity is a primary factor in the resoltttion of both apparent extent and duration, it can be expected that apparent duration is also related to velocity such that a judgment: of longer time is associated with the slower velocity. However, this relationship was found to be insignificant, $\chi^{2}(1)=3.372$, $p>.05$, with a corresponding phi coefficient of $.145(p>.05)$.

The mean PSE for the component extents of the $L$ figure was found to be 18.583 $\mathrm{cm}(S D=1.201 \mathrm{~cm})$, thus confirming the overestimation of the radial movement by $7.085 \%, t(11)=4.085, p<.005$. In summary, the results of Experiment 4 indicate that under conditions that give rise to the haptic $L$ illusion, the relative movement times along radial and tangential directions, in the majority of instances, can be discriminated by the subjects. The data favor an interpretation of the illusion of extent in terms of the differential perception of movement duration rather than velocity.

\section{General Discussion}

As noted by Davidon and Cheng (1964), tangential movements involve distinctly different patterns of muscle activation and motion at the joints compared with radial movements. It is now evident that these differences in the intrinsic properties of the actively moving limb are reflected in the duration and speed of movement. Specifically, apparently longer radial movements are executed slower and for a longer time compared with tangential movements of equal extent. Given such data, a greater elaboration of the differential actions of radial and tangential movement now seens warranted.

In the present study, a purely radial movement involves greater motion at the elbow joint compared with that at the shoulder. In contrast, a purely tangential movement mainly involves abduction and adduction at the shoulder joint with the elbow joint relatively immobile. However, it should be noted that in the earlier study by Day and Wong (1971), the illusion persisted regardless of whether the radial movement involved flexion at the elbow or only rotation at the shoulder joint when the movement was executed with the arm outstretched. This argues against an explanation of the illusion solely in terms of the relative sensitivities of the joints or in terms of the differences afforded by proximal and distal musculature in the density of their spindle innervation and muscle type (Howard \& Templeton, 1966; Matthews, 1972). The possibility that spindle discharges may influence the perception of joint angle and the induction of constant errors of movement (Goodwin, McCloskey, \& Matthews, 1972a, 1972b; Granit, 1972) is recognized, but the present clata are not readily amenable to an interpretation in these terms. It thus seems more appropriate in the following discussion to consider the illusion in terms of the relevant cues that are inherent to the dynamic phase of the movement itself.

With rotational movements of the shoulder joint, the resistance offered by the limb to acceleration depends not only upon the mass but also upon its distribution about the shoulder axis, that is, upon the moment of inertia. The closer the mass is to the axis, the easier it is to turn. Since radial movements are executed with the limb more distal from the shoulder axis compared with tangential movements, the moment of inertia is accordingly greater along radial directions. With a smaller noment of inertia, a limb moving tangentially can be expected 
to accelerate faster and to maintain a greater velocity throughout the extent of movement. ${ }^{2}$ The obtained velocity and duration components of the movements are clearly differentiated in accord with this analysis, but the differences in acceleration characteristics are not as clearly defined.

The obtained relationship between an apparently shorter haptic length with a greater velocity of movement does not appear to be in accord with the physiological evidence that indicates that movements of greater velocity result in the most kinesthetic stimulation (Gibbs, 1954, 1961; Matthews, 1964; Ruch, Patton, Woodbury, \& Towes, 1961). However, if elapsed time of movement is taken as the relevant determinant, then the relationship is accountable in terms of a greater "counting" of existing stimulus elements (Treisman, 1963) for movements of greater duration to give rise to judgments of longer length. This interpretation is endorsed by the finding that the differential time cues are indeed perceptible to the subject. In these terms, it should be noted that the illusion of extent is a further documentation of the interdependence in judgments of space-time relations in line with the tau (Helson \& King, 1931) and tau movement (Ono, 1969) effects found in the studies of psychological relativity.

\footnotetext{
${ }^{2}$ When the tangential component was placed maximally distal from the subject at full arm's length (with $180^{\circ}$ rotation of the $L$ figure), it was judged longer by $1.69 \%(p>.05)$ and $6.02 \%(p<$ .005 ) in the horizontal-front and horizontal-side condition, respectively. For both conditions (with 14 subjects each), the mean tangential movement velocity was also less but not by a significant degree $(p>.05)$ compared with that for the radial movement. As these data are only suggestive, the explanation offered in terms of moments of inertia should not be taken without qualification. This issue merits further investigation.
}

\section{References}

Brooks, V. B., \& Stoney, S. D., Jr. Motor mechanisms: The role of the pyramidal system in motor control. In V. E. Hall (Ed.), Annual revicu of physiology (Vol. 33). Palo Alto, Calif.: Annual Reviews, 1971.

Brown, T. Perception of extension. In W. N.
Dember (Ed.), Visual perception: The ninetconth contury. New York: Wiley, 1964. (Reprinted from Lectures on the philosophy of the human mind (Vol. 1). Edinburgl, Scotland: Tait, 1846.)

Cheng, M. F. H. Tactile-kinesthetic perception of length. American Journal of Psychology, 1968, $81,74-82$.

Davidon, R. S., \& Cheng, M. F. H. Apparent distance in a horizontal plane with tactile kinesthetic stimuli. Quarterly Journal of Experimental Psychology, 1964, 16, 177-281.

Day, R. H., \& Avery, G. C. Absence of the horizontal-vertical illusion in haptic space. Journal of Experimental Psychology, 1970, 83, 172-173.

Day, R. H., \& Wong, T. S. Radial and tangential movement directions as determinants of the haptic illusion in an L figure. Jonmal of Experimental Psychology, 1971, 87, 19-22.

Deregowski, J., \& Ellis, H. D. Effect of stimulus orientation upon haptic perception of the horizontal-vertical illusion. Journal of Experimental Psychology, 1972, 95, 14-19.

Gibbs, C. B. The continuous regulation of skilled responses by kinesthetic feedback. British Journal of Psychology, 1954, 45, 25-39.

Gibbs, C. B. Optimal gain of mantally controlled machines. Toronto, Canada: Defence Research Medical Laboratories, 1961.

Goodwin, G. M., McCloskey, D. I., \& Matthews, P. B. C. The contribution of muscle afferents to kinesthesia shown by vibration induced illusions of movement and by the effects of paralysing joint afferents. Brain, 1972, 95, 705-748. (a)

Goodwin, G. M., McCloskey, D. I., \& Matthews, P. B. C. Proprioceptive illusions induced by muscle vibration: Contribution to perception by muscle spindles? Science, 1972, 175, 1382-1384. (b)

Granit, R. Constant errors in the execution and appreciation of movement. Brain, 1972, 95, 649660.

Helson, H., \& King, S. M. The tau effect: An example of psychological relativity. Journal of $E_{x}$ perimental Psychology, 1931, 14, 202-217.

Howard, I. P., \& Templeton, W. B. Human spatial oricntation. New York: Wiley, 1966.

Jones, F. N. Space-time relationships in somesthetic localization. Science, 1956, 124, 484.

Keele, S. W. Movement control in skilled motor performance. Psychological Bulletin, 1968, 70, 387-403.

Kirk, R, Experimental design: Procedures for the bchavioral sciences. Monterey, Calif.: Brooks/ Cole, 1968.

Matthews, P. B. C. Muscle spindles and their motor control. Physiological Review, 1964, 44, 219-278.

Matthews, P. B. C. Mammalian muscle receptors and their central actions. London: Arnold, 1972.

Ono, A. Interdependence in successive judgments of the duration, distance and speed of a manual movement. Tolnthu Psychologica Folia, 1969, 28, 29-53. 
Reid, R. L. An illusion of movement complimentary to the horizontal-vertical illusion. Quartorly Journal of Exporimental l'sychology, 1954, $6,107-111$.

Ruch, T, C., Patton, H. D., Woodbury, J. W., \& Towes, A. L. Nourophysiology. Philadelphia, Pa.: Saunders, 1961.

Treisman, M. Temporal discrimination and the inclifference interval: Implications for a model of the "internal clock." Psychological Monographs, 1963, $77(13$, Whole No. 576).

Wapner, S., Weinberg, J., Glick, J. A., \& Rand, G. Effect of speed of movement on tactual-kines- thetic perception of extent. American Journal of I'sychology, 1967, 80, 608-613.

Wetherill, G. B. Sequential estimation of quantal response curves. Journal of the Royal Statistical Socicty, 1963, 25, 1-48.

Wetheril, G. B., \& Levitt, H. Sequential estimation of points on a psychometric function. British Journal of Mathcmatical and Statistical Psychol$o g y, 1965,18,1-10$.

Wieland, B. A. The interaction of space and time in cutaneous perception. Ancrican Journal of Psychology, 1960, 73, 248-255.

Received April 23, 1976 